\title{
An Almost Ideal Sharing Scheme for \\ Coalition Games with Externalities
}

Johan Eyckmans

Michael Finus

Stirling Economics Discussion Paper 2009-10

April 2009

Online at http://www.economics.stir.ac.uk 


\title{
An Almost Ideal Sharing Scheme for Coalition Games with Externalities ${ }^{+}$
}

\author{
Johan Eyckmans and Michael Finus* \\ - Katholieke Universiteit Leuven, \\ Centrum voor Economische Studiën and \\ European University College Brussels \\ Stormstraat 2 \\ B-1000 Brussel \\ Belgium \\ E-mail: Johan.Eyckmans@HUBrussel.be \\ *Department of Economics \\ University of Stirling \\ Stirling FK9 4LA, Scotland \\ United Kingdom \\ E-mail: $\underline{\text { michael.finus@stir.ac.uk }}$
}

This version: April, 2009

\begin{abstract}
Cooperative agreements among firms to coordinate R\&D investments and share knowledge or coordination among nations to reduce trade barriers or to provide global public goods usually proves difficult due to free-rider incentives. In this paper, we propose a sharing scheme for the distribution of the gains from cooperation for games with externalities and heterogeneous players in order to mitigate free-rider problems. We show that every sharing rule belonging to our scheme leads to the same set of stable coalitions which is never empty. This scheme is "almost ideal" because it stabilizes those coalitions generating the highest possible global worth among the set of all "potentially stable coalitions". Our Almost Ideal Sharing Scheme is particularly powerful for economic problems where outsiders benefit from the coalition's actions (positive externalities) and which therefore are likely to suffer from severe free-riding.
\end{abstract}

JEL codes: C70, C71

Keywords: coalition games, partition function, externalities, sharing schemes

The authors gratefully acknowledge comments and suggestions by Luc Lauwers, Claude d'Aspremont, Santiago Rubio, Pedro Pintasilgo and Alfred Endres on an early draft as well as research assistance by Carmen Dunsche. This paper has been written while M. Finus was a visiting scholar at the Katholieke Universiteit Leuven, Centrum voor Economische Studiën (Leuven, Belgium). He acknowledges the financial support by the CLIMNEG 2 project funded by the Belgian Federal Science Policy Office. 


\section{Introduction}

It is well-known that the presence of externalities warrants some coordination and cooperation between agents to prevent important welfare losses. By coordinating their strategies, agents can improve, both collectively and individually, upon non-cooperative outcomes as long as the gains from cooperation are shared in accordance with the interests of all participants. Examples of economic problems with externalities are plentiful in the literature and range from output and price setting behavior of firms in imperfect competitive markets (e.g. Deneckere and Davidson 1985 and Yi 1997), R\&D strategies of firms (e.g. PoyagoTheotokay 1995 and Yi and Shin 2000), the provision of public goods like greenhouse gas reduction, the eradication of contagious diseases, like Malaria and AIDS, and the fight against terrorism (e.g. Sandler 2004 for an overview), to coordination of tariffs and monetary policies (e.g. Yi 1996 and Kohler 2002).

In this paper, we show existence, robustness, stability and optimality of an "optimal sharing rule" in the presence of externalities. Our sharing scheme maximizes aggregate welfare subject to the constraint of coalitional stability. We focus on the well-known cartel formation game and the concept of internal and external stability of d'Aspremont et al. (1983): players have only the choice to remain at the fringe (i.e., singleton coalition) or joining the cartel (i.e., non-trivial coalition) and the cartel is called stable if no cartel member has an incentive to leave (internal stability) and no outsider has an incentive to join (external stability) the cartel.

The restriction to single coalition structures has a great benefit because it allows us to derive conclusive results under minimal structural assumptions. Our model does not impose any restriction on the heterogeneity of players and requires only very general and mild structural properties of the game and hence, of the underlying economic problem. Hence, our results are relevant for to many economic externality problems of interest. In addition, our sharing scheme is very flexible because it allows for different sets of sharing weights and game theoretic stability of cooperation is explicitly accounted for as a constraint.

The classical approach of studying the formation of coalitions assumes a transferable utility (TU)-framework and is based on the characteristic function. ${ }^{1}$ This function assigns to every coalition a worth which is the aggregate payoff that a coalition can secure for its members, irrespective of the behavior of players outside this coalition. By construction, the characteristic function approach is ill-suited to deal with problems of externalities, i.e. when

1 An excellent overview is provided in Bloch (2003). 
outsiders' actions affect the worth of a coalition and vice versa (Bloch 2003). ${ }^{2}$ It focuses on the coalition's worth and says nothing about the payoff to outsiders. More importantly, almost exclusively, the focus is on the division of the worth in the grand coalition, despite there are plenty of economic problems were it seems reasonable to expect that the grand coalition will not be stable and hence, will never form.

An alternative approach is based on the concept of the partition function due to Thrall and Lucas (1963). This function assigns a worth to every coalition and singleton in the game and this worth depends on the entire coalition structure, i.e. the partition of players. Since for our analysis information about non-coalition members' payoffs is important, we work in the tradition of the partition function. The main focus of this literature is the prediction of equilibrium coalition structures. Beyond the particularities of different economic problems, it appears that they share common features in terms of the incentives to form coalitions. The most important feature is the kind of payoff externality (positive versus negative externality) that accrues to those players not involved in the expansion of a coalition. This feature proves to be crucial for the success of coalition formation. For instance, it appears from the literature that positive (negative) externalities provide an incentive for players to free-ride (cooperate), leading to small (large) stable coalitions. Typical examples of positive externalities are for instance output and price cartels and public good agreements. Firms not involved in an output cartel benefit from lower output by the cartel via higher market prices. This is also the driving force in price cartels where the cartel raises prices above non-cooperative levels. Similarly, agents not involved in a public good agreement benefit from higher provision levels of participants. In contrast, countries forming customs unions that abolish taxes among members but impose a common external tariff on outsiders may exhibit a negative externality on nonmembers. ${ }^{3}$

Intuitively, it is clear that the degree and sustainability of cooperation depends crucially on the division of the gains from cooperation. There is some literature on the axiomatic underpinning of surplus sharing rules in the context of the partition function approach; see e.g. Meyerson (1977) and Bolger (1989). However, this literature often just assumes that cooperation among all agents (i.e. grand coalition) is stable instead of showing that it is the equilibrium outcome of some non-cooperative coalition formation game; see de Clippel and Serrano (2005). In

2 A notable exception is the $\gamma$-characteristic function introduced by Chander and Tulkens (1995, 1997) which assumes that outsiders play a Nash equilibrium strategy against the coalition.

3 See Bloch (2003) and Yi (2003) for details and other examples. See also section 5 for a discussion. 
contrast to this literature, we consider stability as a necessary condition for sustainable cooperation and hence as a starting point of our analysis.

Up to now, the literature using the partition function has paid little attention to the division of the gains from cooperation subject to the constraint of coalitional stability. Due to the complexity of the partition function, most papers assume a fixed sharing rule. One set of papers, which comprises the bulk of the literature, assumes ex-ante symmetric players with equal sharing. ${ }^{4}$ This is probably mainly done for analytical tractability. However, symmetry is a strong assumption that is difficult to justify in most economic environments. Another set of papers - mainly related to the analysis of public good agreements with special focus on international environmental agreements ${ }^{5}$ - allows for asymmetric players but makes ad hoc assumptions about particular (exogenous) sharing rules, most of which are classical game theoretic solution concepts or modifications of them. Clearly, this approach is also not fully satisfactory for at least three reasons. First, none of these sharing rules guarantees existence of a stable equilibrium coalition structure. Second, the prediction of equilibrium coalition structures is extremely sensitive to the particular specification of sharing rules. Third, it remains an open question whether there exist perhaps other sharing rules that perform better in terms of the aggregate worth, letting alone whether there exists a sharing rule that is "optimal" in the sense that it maximizes the aggregate worth subject to the condition that the underlying coalition structure is stable.

We improve over this literature by constructing a sharing scheme that maximizes aggregate welfare subject to coalitional stability in the sense of d'Aspremont et al. (1983). A central concept in our analysis is the notion of Potentially Internally Stable (PIS) coalitions. Loosely speaking, PIS coalitions generate sufficient surplus to satisfy the free-rider claims of all members. For this reason we call our sharing scheme "Almost Ideal Sharing Scheme" (AISS) as - in the presence of externalities - it may only be possible to stabilize a subset of the set of coalitions through a sharing rule, namely only those that are "potentially internally stable". Hence, adopting the Almost Ideal Sharing Scheme does not necessarily lead to efficiency in the sense that the grand coalition forms. This will be particularly relevant for positive externality games in which large coalitions are typically not potentially internally stable due to strong free-rider incentives. ${ }^{6}$ It is for this reason that our analysis mainly focuses on

4 See the literature cited in Bloch (2003) and Yi (1997 and 2003).

5 See for instance Barrett (1997 and 2001), Bosello et al. (2003), Botteon and Carraro (1997) and Eyckmans and Finus (2007).

6 For examples, see the literature cited in footnote 4, the literature cited in Bloch (2003) and Yi (2003) and our discussion in section 5. 
positive externalities, though we will also mention results for negative externality games in passing. "Sharing scheme" indicates that we do not propose a particular solution but are much more general in considering an entire class or set of sharing rules.

In the following, we introduce some notation and definitions in section 2. Section 3 introduces our sharing scheme and we report on our results in section 4. Section 5 discusses economic examples in the literature to which our results apply. Finally, section 6 summarizes the main findings and points to some issues of future research.

\section{Preliminaries}

Let a coalition game between $\mathrm{n} \geq 2$ players be denoted by $\Gamma(\mathrm{N}, \pi)$. The set of players is $\mathrm{N}=\{1, \ldots, \mathrm{n}\}$ and the set of all possible coalitions of $\mathrm{N}$ is denoted by $2^{\mathrm{N}}$, i.e., the power set of $\mathrm{N}$. A coalition $\mathrm{S}$ is a subset of $\mathrm{N}$. In this paper, we restrict attention to coalition structures consisting of no more than one non-trivial or non-singleton coalition $\mathrm{S}$ (the cartel) while all other players $\mathrm{j} \in \mathrm{N} \backslash \mathrm{S}$ are singletons (the fringe). Then, a coalition structure is fully characterized by coalition $\mathrm{S}$. We define a partition function $\pi$ that assigns a single real number $\pi_{S}(S)$ to coalition $S$ and real numbers $\pi_{j}(S)$ to every singleton $j \in N \backslash S$ at the fringe as follows:

$$
\pi: S \mapsto \pi(S)=\left(\pi_{S}(S), \pi_{j}(S)\right) \in \mathbb{R}^{1+(n-s)} \quad \text { with } \quad j \in N \backslash S
$$

In other words, $\pi_{S}(S)$ is the worth of the coalition, i.e. the aggregate payoff of coalition $S$, and $\pi_{j}(S)$ the worth or payoff of a singleton. The domain of this partition function is the power set of $\mathrm{N}$. The image of this mapping is a vector of variable size $(1+(\mathrm{n}-\mathrm{s}))$, depending on $\mathrm{s}$, i.e., the cardinality of coalition $\mathrm{S}$, and on $\mathrm{n}$, the total number of players. Our partition function is simpler than general partition functions (see, e.g., Bloch 2003 and Yi 2003) since we disregard all partitions that consist of two or more non-trivial coalitions. In contrast to the characteristic function, our partition function assigns not only a worth to coalition $\mathrm{S}$ but also to the non-members of $\mathrm{S}$. This is important because information on the payoff to players outside the coalition is indispensable for analyzing the incentives to leave or join a coalition in games with externalities.

For the analysis of the incentives of players to form coalitions, we have to take one more step: it is not the aggregate payoff to a coalition but the individual payoffs to coalition members that matters. This type of information is contained in the valuation function, mapping coalition structures into a vector of individual payoffs - called valuations. In our setting, a 
valuation function assigns to every coalition $\mathrm{S}$ of $\mathrm{N}$ a real-valued vector of length $\mathrm{n}$, $\mathrm{v}: 2^{\mathrm{N}} \rightarrow \mathbb{R}^{\mathrm{n}}: \mathrm{S} \mapsto \mathrm{v}(\mathrm{S})$, such that:

[2]

$$
\left\{\begin{aligned}
\sum_{\mathrm{i} \in \mathrm{S}} \mathrm{v}_{\mathrm{i}}(\mathrm{S}) & =\pi_{\mathrm{S}}(\mathrm{S}) \\
\mathrm{v}_{\mathrm{j}}(\mathrm{S}) & =\pi_{\mathrm{j}}(\mathrm{S}) \quad \forall \mathrm{j} \in \mathrm{N} \backslash \mathrm{S} .
\end{aligned}\right.
$$

This means that for every coalition $\mathrm{S}$, the valuation function $\mathrm{v}$ specifies how the worth of coalition $S$ is allocated among its members. By construction, valuations $v_{i}(S)$ are group rational, i.e. the entire worth of coalition $S, \pi_{S}(S)$ is distributed among its members. For every outsider to coalition $S$, the valuation $v_{j}(S)$ coincides with the worth $\pi_{j}(S)$ that is assigned to him by the partition function.

Note the difference between the concept of a valuation and an imputation known from the characteristic function. An imputation is usually only one vector of length $n$, listing the payoff to each player in the grand coalition $(\mathrm{S}=\mathrm{N})$ whereas a valuation function assigns vectors of length $\mathrm{n}$ to every possible coalition structure, specifying individual payoffs not only for coalition members but also for outsiders. ${ }^{7}$ This more comprehensive view is necessary to capture externalities across coalitions and players. In the presence of externalities, it may no longer be true that the grand coalition is stable. This is particular relevant for many economic problems where the formation of coalitions implies positive spillovers to outsiders as this is illustrated in Bloch (2003) and Yi (1997, 2003). Then, players have a strong incentive to remain outsiders and only small coalitions are stable. Surprisingly, this free-rider problem may not even disappear if coalition formation is associated with superadditivity which means that the aggregate payoff to all players involved in forming larger coalitions increases. In these cases, the superadditivity effect is smaller than the free-rider effect due to positive externalities. This will be illustrated in the numerical example below and confirmed for many economic problems that we discuss in section 5. In order to leave no doubts what we mean with externalities and superadditivity, we define these properties subsequently.

\section{Definition 1: Positive and Negative Externalities}

A coalition game $\Gamma(\mathrm{N}, \pi)$ exhibits positive externalities if and only if its partition function $\pi$ satisfies: $\quad \forall \mathrm{S} \subseteq \mathrm{N}, \forall \mathrm{j} \neq \mathrm{i}, \mathrm{j} \notin \mathrm{S}: \pi_{\mathrm{j}}(\mathrm{S}) \geq \pi_{\mathrm{j}}(\mathrm{S} \backslash\{\mathrm{i}\}) \quad$ and $\quad \exists \mathrm{k} \neq \mathrm{i}, \mathrm{k} \notin \mathrm{S}: \quad \pi_{\mathrm{k}}(\mathrm{S})>\pi_{\mathrm{k}}(\mathrm{S} \backslash\{\mathrm{i}\})$.

7 An exception is Aumann and Drèze (1974) who consider various solution concepts not only for the grand coalition but also for any partition of players. We will apply some of their concepts to the example we introduce below in the context of the partition function. 
That is, a positive externality implies that no outsider not involved in the enlargement of the coalition is worse off and it least one outsider is strictly better off.

A coalition game exhibits negative externalities if and only if its partition function $\pi$ satisfies: $\forall \mathrm{S} \subseteq \mathrm{N}, \forall \mathrm{j} \neq \mathrm{i}, \mathrm{j} \notin \mathrm{S}: \pi_{\mathrm{j}}(\mathrm{S}) \leq \pi_{\mathrm{j}}(\mathrm{S} \backslash\{\mathrm{i}\})$ and $\exists \mathrm{k} \neq \mathrm{i}, \mathrm{k} \notin \mathrm{S}: \pi_{\mathrm{k}}(\mathrm{S})<\pi_{\mathrm{k}}(\mathrm{S} \backslash\{\mathrm{i}\})$.

That is, a negative externality implies that no outsider not involved in the enlargement of the coalition is better off and it least one outsider is strictly worse off.

We assume a strict positive (negative) effect for at least one outsider in order to rule out neutral effects of coalition formation. It is apparent that negative externalities are the mirror image of positive externalities. Note that we only call a game a positive (negative) externality game if this effect holds for all coalitions. If we have to make specific assumptions about the kind of externality in the sequel at all (which is not always the case), we will focus on games with positive externalities. Due to the free-rider problem, this type of economic problems makes it interesting to analyze devices aiming at improving the prospects of successful cooperation. In contrast, in negative externality games, the grand coalition typically emerges as a stable coalition as outsiders have an incentive to join the coalition (Maskin 2003). Nevertheless, we will mention some results about negative externality games in passing.

\section{Definition 2: Superadditivity}

A coalition game $\Gamma(\mathrm{N}, \pi)$ is superadditive if and only if its partition function $\pi$ satisfies: $\forall \mathrm{S} \subseteq \mathrm{N}, \forall \mathrm{i} \in \mathrm{S}: \pi_{\mathrm{S}}(\mathrm{S}) \geq \pi_{\mathrm{S} \backslash\{\mathrm{i}\}}(\mathrm{S} \backslash\{\mathrm{i}\})+\pi_{\mathrm{i}}(\mathrm{S} \backslash\{\mathrm{i}\})$. That is, the aggregate payoff of those players involved in the enlargement of a coalition does not decrease.

Superadditivity is often motivated by arguing that "even if two coalitions merge, they always have the option of behaving as they did when they were separate, and so their total payoff should not fall” (Maskin 2003, p. 9). However, this argument can only be applied to coalition games if the strategies of players not involved in a merger remain fixed (Bloch 2003). For many economic problems with externalities, however, this is generally not true as will be evident from the examples discussed in section 5. Note that - as with the kind of externality we will make use of the property superadditivity only in a limited number of cases and then it will be explicitly mentioned. Again, a coalition game is only called superadditivity if this property holds for all possible coalitions $\mathrm{S}$.

It may be worthwhile to note from a normative point of view that if a coalition game is characterized by superadditivity and positive externalities, then aggregate welfare of all players increases when coalitions become gradually larger. For negative externality games, 
this conclusion cannot be drawn though the grand coalition usually generates the highest global welfare (see more on this in section 5).

We complete our fundamental definitions by introducing the notion of stable coalitions according to d'Aspremont et al. (1983) as used in this paper.

\section{Definition 3: Internally and Externally Stable Coalitions ${ }^{8}$}

Let $\mathrm{v}$ be a valuation function for coalition game $\Gamma(\mathrm{N}, \pi)$ and $\mathrm{v}(\mathrm{S}) \in \mathbb{R}^{\mathrm{n}}$ the vector of valuations for the players in $\mathrm{N}$ when coalition $\mathrm{S}$ forms. Coalition $\mathrm{S}$ is stable with respect to the valuations $\mathrm{v}(\mathrm{S})$ if and only if:

- internal stability (IS): $\quad \mathrm{v}_{\mathrm{i}}(\mathrm{S}) \geq \mathrm{v}_{\mathrm{i}}(\mathrm{S} \backslash\{\mathrm{i}\}) \quad \forall \mathrm{i} \in \mathrm{S}$

- $\quad$ external stability $(E S): \quad \mathrm{v}_{\mathrm{j}}(\mathrm{S}) \geq \mathrm{v}_{\mathrm{j}}(\mathrm{S} \cup\{\mathrm{j}\}) \quad \forall \mathrm{j} \in \mathrm{N} \backslash \mathrm{S}$.

That is, coalition $\mathrm{S}$ is stable if no insider wants to leave and no outsider wants to join coalition S.

As there are many ways to share the coalitional worth in a coalition game $\Gamma(\mathrm{N}, \pi)$, there are many possible valuation functions that can be derived from its partition function. Consequently, a coalition S may be stable with respect to a particular valuation function $\mathrm{v}$ but may not be stable with respect to another valuation function $\mathrm{v}^{\prime}$. Therefore, we denote the set of coalitions that are internally stable with respect to valuation function $\mathrm{v}$ by $\Sigma^{\mathrm{IS}}(\mathrm{v})$, the set of coalitions that are externally stable by $\Sigma^{\mathrm{ES}}(\mathrm{v})$ and the set of stable coalitions by $\Sigma^{\mathrm{S}}(\mathrm{v})=\Sigma^{\mathrm{IS}}(\mathrm{v}) \cap \Sigma^{\mathrm{ES}}(\mathrm{v})$.

\section{Numerical Example}

In order to illustrate some results in the course of the following discussion, we provide a numerical example in the Appendix. The example assumes four players and a partition function that exhibits positive externalities and superadditivity (see Table A1 in the Appendix). For three prominent sharing rules, i.e., the Shapley Value, the Nucleolus and the Nash Bargaining Solution internally and externally stable coalitions are displayed. Shapley Value and Nucleolus are extended versions as defined in Aumann and Drèze (1974), meaning

8 Note that this definition basically corresponds to a Nash equilibrium in which no player has an incentive to revise his "announcement" whether to be a member of coalition S or not. It implies open membership as all players are free to join the coalition. Moreover, note that the terminology internal and external stability has also been used in the context of other solution concepts like for instance the "stable set". We use Definition 3 because this splits stability into two parts that can be sequentially analyzed. 
that these values are computed not only for the grand coalition but for every nonempty coalition $\mathrm{S} \subseteq \mathrm{N}$ (see Tables $\mathrm{A} 2$ and $\mathrm{A} 3$ in the Appendix). This also applies to the Nash Bargaining Solution, though shares depend on the weights assigned to different players. We consider two versions: equal and unequal weights (see Tables A4 and A5 in the Appendix).

Tables A1 to A5 in the Appendix stress three points made in the introduction. First, a stable coalition may not always exist. Indeed, in this example, we find no stable coalition for the Shapley Value (Table A2) and the Nash Bargaining Solution with equal weights (Table A4). Second, the set of stable coalitions is sensitive to the sharing rule. For instance for the two versions of the Nash Bargaining solution, there exists one stable coalition in the case of unequal weights (Table A5) but there is no stable coalition in the case of equal weights (Table A4). Third, the examples do not provide a hint as to whether there are other sharing rules leading perhaps to more stable coalitions and in particular leading to stable coalitions with higher aggregate worth. In the following section, we claim that there does indeed exist such a sharing rule: the Almost Ideal Sharing Scheme (AISS).

\section{Almost Ideal Sharing Scheme: Concept}

Since it is our ambition to study the impact of coalitional surplus sharing rules on the stability of coalitions in a general framework, the use of one specific sharing rule would be too restrictive. Therefore, we introduce a class of sharing rules and study the properties of its members. Recall from the definition of a valuation function that there corresponds to every surplus sharing rule a particular valuation function. Hence, speaking about a sharing rule is equivalent to speaking about a valuation function and it is the latter terminology that we will use in the remainder of this paper. In particular, we will use the term "Almost Ideal Sharing Scheme" (AISS) to denote the entire class of "Almost Ideal Valuation Functions" (AIVFs). Hence, an "Almost Ideal Valuation Function" (AIVF) is a particular member in the class AISS

The main motivation for the development of the AISS is to remedy free-riding in the context of positive externalities, though it turns out that the AISS does an excellent job in negative externality games as well. In the context of positive externalities, associated with the problem of forming large stable coalitions, it appears that one is more concerned about those players leaving the coalition than about those players joining it. Hence, the most immediate notion of free-riding seems to be related to the violation of internal stability, although we are aware that stability also comprises external stability. Therefore, the motivation and the analysis of the AISS start from internal stability and subsequently we consider also external stability. 
The construction of the AISS sets off by the observation that a necessary and sufficient condition for internal stability of coalition $\mathrm{S}$ is that each player in $\mathrm{S}$ receives his outside payoff. In the cartel formation game, the free-rider payoffs are associated with the scenario in which an individual coalition member leaves coalition $\mathrm{S}$ in order to become a singleton while the remaining members of coalition $\mathrm{S}$ continue to cooperate. These payoffs constitute lower bounds on the claims of individual coalition members with respect to the coalitional surplus in order to refrain from leaving the coalition. More specifically:

\section{Definition 4: Almost Ideal Valuation Function}

An Almost Ideal Valuation Function (AIVF) for coalition game $\Gamma(N, \pi)$ is a valuation function $\mathrm{v}^{\operatorname{AIVF}(\lambda)}$ that satisfies:

$\forall \mathrm{S} \subseteq \mathrm{N}:\left\{\begin{array}{l}\forall \mathrm{i} \in \mathrm{S}: \quad \mathrm{v}_{\mathrm{i}}^{\operatorname{AIVF}(\lambda)}(\mathrm{S})=\pi_{\mathrm{i}}(\mathrm{S} \backslash\{\mathrm{i}\})+\lambda_{\mathrm{i}}(\mathrm{S}) \sigma(\mathrm{S}) \\ \forall \mathrm{j} \in \mathrm{N} \backslash \mathrm{S}: \mathrm{v}_{\mathrm{j}}^{\operatorname{AIVF}(\lambda)}(\mathrm{S})=\pi_{\mathrm{j}}(\mathrm{S})\end{array}\right.$

with $\lambda(\mathrm{S}) \in \Delta^{\mathrm{s}-1}=\left\{\lambda \in \mathbb{R}_{+}^{\mathrm{s}} \mid \sum_{\mathrm{j} \in \mathrm{S}} \lambda_{\mathrm{j}}=1\right\}$ and $\sigma(\mathrm{S})=\pi_{\mathrm{S}}(\mathrm{S})-\sum_{\mathrm{i} \in \mathrm{S}} \pi_{\mathrm{i}}(\mathrm{S} \backslash\{\mathrm{i}\})$

where $\Delta^{s-1}$ denotes the set of all possible sharing weights of a coalition with s players and $\sigma(\mathrm{S})$ denotes the surplus (or deficit) of coalition $\mathrm{S}$ over the sum of free-rider payoffs $\pi_{\mathrm{i}}(\mathrm{S} \backslash\{\mathrm{i}\})$ of its members. That is, an AIVF allocates to each coalition member its free-rider payoff, plus some non-negative share of the remaining surplus where shares add up to one.

One obvious interpretation of our definition is that the free-rider payoff $\pi_{\mathrm{i}}(\mathrm{S} \backslash\{\mathrm{i}\})$ is the threat point of player $i$ in coalition $S$ and weight $\lambda_{i}(S)$ is the bargaining power of player $i \in S .{ }^{9}$ Hence, an AIVF may be seen as an extension of a Nash bargaining solution (for transferable utility games) in the context of coalition games. However, different from the Nash bargaining solution, the threat point is not fixed but depends on the coalition structure. For instance, if S gradually increases through the accession of players, the threat point $\pi_{\mathrm{i}}(\mathrm{S} \backslash\{\mathrm{i}\})$ will also gradually increase (decrease) with positive (negative) externalities.

It is important to point out that there are as many Almost Ideal Valuation Functions (AIVFs) for a coalition game $\Gamma(\mathrm{N}, \pi)$ as there are ways to share - in every possible coalition $\mathrm{S}$ of $\mathrm{N}$ — the coalition surplus $\sigma(\mathrm{S})$ among its members. The set of all AIVFs for game $\Gamma(\mathrm{N}, \pi)$ will be denoted by $\mathcal{V}(\Gamma)$ and constitutes the Almost Ideal Sharing Scheme (AISS). Despite every AIVF is defined for specific sharing weights $\lambda(\mathrm{S})$, the class of AIVFs, constituting our AISS,

9 In the context of international environmental agreements, weights have also been associated with different notions of fairness. See for instance, Eyckmans and Finus (2007) and Weikard et al. (2006). 
does not require assumptions about weights as long as they are non-negative and sum up to one for each coalition $\mathrm{S}$ of $\mathrm{N}$. This stresses that - different from most cooperative solution concepts, e.g., Shapley Value and Nucleolus - we are not interested in assigning a unique value to each player in some coalition S. Instead, we find it more appealing that weights do not matter for all our subsequent results, i.e. results hold for the entire class of AIVFs.

Before turning to our last definition, it is important to point out that in some coalitions the free-rider incentives may be so strong that it is not possible to satisfy the claims of all coalition members, i.e. $\sigma(\mathrm{S})<0$. In this case, the AIVF will share the deficit according to weights $\lambda(\mathrm{S})$, as the numerical example in the Appendix illustrates and on which we comment below.

In order to facilitate the subsequent analysis, it will prove useful to classify coalitions according to the following criterion.

\section{Definition 5: Potentially Internally Stable Coalitions}

A coalition $\mathrm{S}$ is called potentially internally stable (PIS) for partition function $\pi$ if and only if: $\pi_{\mathrm{S}}(\mathrm{S}) \geq \sum_{\mathrm{i} \in \mathrm{S}} \pi_{\mathrm{i}}(\mathrm{S} \backslash\{\mathrm{i}\})$, i.e., $\sigma(\mathrm{S}) \geq 0$. That is, a coalition is potential internally stable if the aggregate payoff to the coalition is not smaller than the sum of free-rider payoffs of its members.

Note that we have related potential internal stability to the property of the partition function as only aggregate payoffs matter whereas internal stability (IS) and external stability (ES) are (and have to be) properties of a valuation function as individual payoffs matter. We denote the set of coalitions that are PIS for a particular partition function $\pi$ by $\Sigma^{\mathrm{PIS}}(\pi)$.

\section{Numerical example resumed}

In the example in the Appendix, the singleton coalitions structure, all coalitions with two players and two out of the four coalitions with three players are PIS (see Table A1, column 10). This confirms that not all coalitions may be potentially internally stable, in particular not the grand coalition. For instance, in the grand coalition, the aggregate payoff is $172 / 3$ (Table A1, column 7 , last row) whereas the sum of free-rider payoffs is $18 \frac{2}{3}=4 \frac{1}{3}+7+3+4 \frac{1}{3}$ (Table A1, column 8, last row). Hence, the surplus is negative $(\sigma(\mathrm{S})=-1=172 / 3-182 / 3)$ and the AIVF assumed in Table A6 shares the deficit among all players with valuations $4 \frac{1}{12}, 63 / 4,23 / 4$ and $4 \frac{1}{12}$, respectively (see last row in Table A6). The intuition is that although the worth of the coalition increases with additional members due to superadditivity, the free-rider incentive increases even more due to positive externalities. 
Table A6 displays results for our concept of an Almost Ideal Valuation Function (AIVF). Though the example assumes equal sharing weights, we will show below that this assumption does not matter. That is, the set of internally and externally stable coalitions is unaffected by the assumption on weights. The AIVF in the example achieves internal stability for all nine PIS coalitions (i.e. compare Table A1, column 10 with Table A6, column 7). This observation will be generalized in Lemma 1 below. In contrast, the other three solution concepts considered in this example can only ensure internal stability of the singleton coalition structure and of all coalitions with two players (Tables A2 to A5, column 7) and hence only of seven out of nine potentially stable coalitions. That is, the two PIS coalitions with three members are not internally stable for these solution concepts.

\section{Almost Ideal Sharing Scheme: Results}

In the following, we group results into four subsections in order to stress the underlying assumptions required to establish them. In subsection 4.1, no assumption at all regarding the valuation function is required. Hence, results hold for all economic problems we can think of. In subsection 4.2, we present results that apply to positive externality games only and in section 4.3 we focus on superadditive games only. Finally, we discuss some results that apply to negative externality games in section 4.4 .

\subsection{General Results}

The construction of Almost Ideal Valuation Functions (AIVFs) in Definition 4 suggests that they are designed to remedy free-riding in terms of internal stability. Therefore, Lemma 1 shows that every coalition that is potentially internally stable will be internally stable for any AIVF.

\section{Lemma 1: AISS and Potential Internal Stability}

Coalition $\mathrm{S} \subseteq \mathrm{N}$ is potentially internally stable if and only if $\mathrm{S}$ is internally stable for any $\mathrm{v}^{\operatorname{AIVF}(\lambda)} \in \mathcal{V}(\Gamma)$.

Proof: $\Rightarrow$ Suppose that coalition S was PIS, implying $\sigma(S) \geq 0$ by Definition 5 , but assume to the contrary that there existed a valuation $\mathrm{v}^{\operatorname{AIVF}(\lambda)} \in \mathcal{V}(\Gamma)$ such that coalition $\mathrm{S}$ would not be internally stable with respect to this valuation function. Thus, $\pi_{\mathrm{i}}(\mathrm{S} \backslash\{\mathrm{i}\})+\lambda_{\mathrm{i}}(\mathrm{S}) \sigma(\mathrm{S})=$ $\mathrm{v}_{\mathrm{i}}^{\operatorname{AIVF}(\lambda)}(\mathrm{S})<\mathrm{v}_{\mathrm{i}}^{\operatorname{AIVF}(\lambda)}(\mathrm{S} \backslash\{\mathrm{i}\})=\pi_{\mathrm{i}}(\mathrm{S} \backslash\{\mathrm{i}\})$ which implies $\sigma(\mathrm{S})<0$ and therefore contradicts the initial assumption.

$\Leftarrow$ If $\mathrm{S}$ is internally stable for any $\mathrm{v}^{\operatorname{AIVF}(\lambda)} \in \mathcal{V}(\Gamma)$, then it follows that $\forall \mathrm{i} \in \mathrm{S}$ : $\mathrm{v}_{\mathrm{i}}^{\operatorname{AIVF}(\lambda)}(\mathrm{S}) \geq \mathrm{v}_{\mathrm{i}}^{\operatorname{AIVF}(\lambda)}(\mathrm{S} \backslash\{\mathrm{i}\})=\pi_{\mathrm{i}}(\mathrm{S} \backslash\{\mathrm{i}\})$. Taking sums over all members in $\mathrm{S}$ and using the 
definition of AIVF yields $\sum_{\mathrm{j} \in \mathrm{S}}\left[\pi_{\mathrm{j}}(\mathrm{S} \backslash\{\mathrm{j}\})+\lambda_{\mathrm{j}}(\mathrm{S}) \sigma(\mathrm{S})\right] \geq \sum_{\mathrm{j} \in \mathrm{S}} \pi_{\mathrm{j}}(\mathrm{S} \backslash\{\mathrm{j}\})$ and hence $\sigma(\mathrm{S}) \geq 0$. From Definition 5, it therefore follows that S is PIS. QED

The importance of Lemma 1 derives from three facts. First, internal stability is a necessary condition for a stable coalition, but is often violated for larger coalitions in positive externality games as this appears from the literature (see footnote 5) and as the numerical example in the Appendix confirms. Second, every AIVF ensures that every coalition that is potentially internally stable will actually be internally stable. Other solution concepts may miss this potential substantially, as this is illustrated by the numerical example in the Appendix. Third, there is some degree of freedom in the choice of the sharing rule (through the choice of weights $\lambda(S))$ when aiming at stabilizing coalitions internally. This degree of freedom also holds for all subsequent results. On the way to these results, we establish first Lemma 2 which will turn out to be useful in the sequel because it establishes an important link between internal and external stability for every member of the Almost Ideal Sharing Scheme (AISS).

\section{Lemma 2: AISS, Externally and Potentially Internally Stable Coalitions}

Consider a coalition game $\Gamma(\mathrm{N}, \pi)$ and a valuation function $\mathrm{v}^{\operatorname{AIVF}(\lambda)} \in \mathcal{V}(\Gamma)$. If coalition $\mathrm{S}$ is not externally stable with respect to $\mathrm{v}^{\operatorname{AIVF}(\lambda)}$, then there exists a $\mathrm{j} \in \mathrm{N} \backslash \mathrm{S}$ such that coalition $\mathrm{S} \cup\{\mathrm{j}\}$ is potentially internally stable.

Proof: If coalition $\mathrm{S}$ is not externally stable with respect to $\mathrm{v}^{\operatorname{AIVF}(\lambda)}$, then it follows from Definition 2 that: $\exists j \in N \backslash S: v_{j}^{\operatorname{AIVF}(\lambda)}(S \cup\{j\})>v_{j}^{\operatorname{AVVF}(\lambda)}(S)$. This is equivalent to $\pi_{j}(S)+$ $\lambda_{\mathrm{j}}(\mathrm{S} \cup\{\mathrm{j}\}) \sigma(\mathrm{S} \cup\{\mathrm{j}\})>\pi_{\mathrm{j}}(\mathrm{S})$ or $\sigma(\mathrm{S} \cup\{\mathrm{j}\})>0$, implying that $\mathrm{S} \cup\{\mathrm{j}\}$ is PIS. QED

It is important to note that Lemma 2 is a distinctive property of the class of AIVFs and may not hold for other valuation functions as this is evident from the example in the Appendix. For instance for the Shapley value in Table A2, coalition $\{\mathrm{c}, \mathrm{d}\}$ is not externally stable and neither $\{\mathrm{a}, \mathrm{c}, \mathrm{d}\}$ nor $\{\mathrm{b}, \mathrm{c}, \mathrm{d}\}$ is PIS.

Using Lemma 1 and 2, we now establish our first main result - the existence of a stable coalition under the AISS. This result does not apply to other sharing rules as the numerical example in the Appendix clearly demonstrates. Recall, in the example, there is no stable coalition for the Shapley value (see Table A2).

\section{Proposition 1: AISS and Existence of a Stable Coalition}

Consider a coalition game $\Gamma(\mathrm{N}, \pi)$ and the class of AIVFs $\mathcal{V}(\Gamma)$. For any $\mathrm{v}^{\operatorname{AIVF}(\lambda)} \in \mathcal{V}(\Gamma)$, there exists at least one stable coalition. 
Proof: By definition, the trivial coalition $S=\{i\}$ is internally stable. If it is also externally stable, we are done. However, suppose the trivial coalition is not externally stable, then there exists at least one two-player coalition that is PIS by Lemma 2 and which is internally stable for any $\mathrm{v}^{\operatorname{AIVF}(\lambda)} \in \mathcal{V}(\Gamma)$ by Lemma 1. Again, if one of the two-player coalitions is also externally stable, we are done. Continuing with this reasoning, it is evident that some coalition $\mathrm{S} \subseteq \mathrm{N}$ will be internally and externally stable, noting that $\mathrm{S}=\mathrm{N}$ is externally stable by definition. QED

It should be noted that the line of reasoning in this proof follows d'Aspremont et al. (1983). However, due to Lemma 2, we do not have to assume symmetric valuations for all players in S, i.e. $v_{\mathrm{i}}(\mathrm{S})=\mathrm{v}_{\mathrm{j}}(\mathrm{S}) \quad \forall \mathrm{i}, \mathrm{j} \in \mathrm{S}$, nor symmetric valuations for all non-member, i.e. $\mathrm{v}_{\mathrm{k}}(\mathrm{S})=\mathrm{v}_{\ell}(\mathrm{S}) \forall \mathrm{k}, \ell \notin \mathrm{S}$, as this is done $\mathrm{d}^{\prime}$ Aspremont et al. and in much of the literature (see Bloch 2003 and Yi 1997). Also no structural assumption about the underlying economic model is required and hence about the properties of the coalition game.

We now turn to our second main result which shows that the set of stable coalitions is independent of the weights assumed for a particular AIVF belonging to the AISS. Hence, it constitutes an invariance or robustness result. This sharply contrasts with the literature on heterogeneous players (see footnote 4) and is also illustrated by our example in the Appendix, stressing that the various "conventional" sharing rules lead to different stable coalitions.

\section{Proposition 2: AISS and Robustness}

Consider a coalition game $\Gamma(\mathrm{N}, \pi)$ and the AISS class of valuation functions $\mathcal{V}(\Gamma)$. Let $\mathrm{v}^{\operatorname{AIVF}(\lambda)}$ and $\mathrm{v}^{\operatorname{AIVF}\left(\lambda^{\prime}\right)}$ be two AIVFs in $\mathcal{V}(\Gamma)$, then i) $\Sigma^{\operatorname{IS}}\left(\mathrm{v}^{\operatorname{AIVF}(\lambda)}\right)=\Sigma^{\operatorname{IS}}\left(\mathrm{v}^{\operatorname{AIVF}\left(\lambda^{\prime}\right)}\right)$, ii) $\Sigma^{\mathrm{ES}}\left(\mathrm{v}^{\operatorname{AIVF}(\lambda)}\right)=\Sigma^{\mathrm{ES}}\left(\mathrm{v}^{\operatorname{AIVF}\left(\lambda^{\prime}\right)}\right)$ and iii) $\Sigma^{\mathrm{S}}\left(\mathrm{v}^{\operatorname{AIVF}(\lambda)}\right)=\Sigma^{\mathrm{S}}\left(\mathrm{v}^{\operatorname{AIVF}\left(\lambda^{\prime}\right)}\right)$. That is, for every Almost Ideal Valuation Function belonging to the AISS, irrespective of weights, the set of internally and externally stable and hence stable coalitions is the same.

Proof: i) Follows from Lemma 1. ii) We prove $\Sigma^{\mathrm{ES}}\left(\mathrm{v}^{\operatorname{AIVF}(\lambda)}\right)=\Sigma^{\mathrm{ES}}\left(\mathrm{v}^{\mathrm{AIVF}\left(\lambda^{\prime}\right)}\right)$ by showing that $\mathrm{S} \notin \Sigma^{\mathrm{ES}}\left(\mathrm{v}^{\operatorname{AIVF}(\lambda)}\right) \Leftrightarrow \mathrm{S} \notin \Sigma^{\mathrm{ES}}\left(\mathrm{v}^{\operatorname{AIVF}\left(\lambda^{\prime}\right)}\right) . \Rightarrow$ Note that $\mathrm{S} \notin \Sigma^{\mathrm{ES}}\left(\mathrm{v}^{\operatorname{AIVF}(\lambda)}\right)$ implies $\exists \mathrm{j} \in \mathrm{N} \backslash \mathrm{S}$ : $\sigma(S \cup\{j\})>0$ according to the proof of Lemma 1. Therefore, $v_{j}^{\operatorname{AIVF}\left(\lambda^{\prime}\right)}(S \cup\{j\})=\pi_{j}(S)+$ $\lambda_{\mathrm{j}}^{\prime}(\mathrm{S} \cup\{\mathrm{j}\}) \sigma(\mathrm{S} \cup\{\mathrm{j}\})>\pi_{\mathrm{j}}(\mathrm{S})=\mathrm{v}_{\mathrm{j}}^{\operatorname{AIVF}\left(\lambda^{\prime}\right)}(\mathrm{S})$ which implies $\mathrm{S} \notin \Sigma^{\mathrm{ES}}\left(\mathrm{v}^{\operatorname{AIVF}\left(\lambda^{\prime}\right)}\right) . \Leftarrow$ Follows from a similar argument, interchanging the role of $\lambda$ and $\lambda^{\prime}$. iii) Follows immediately from i), ii) and the definition of stability, i.e. $\Sigma^{\mathrm{S}}(\mathrm{v})=\Sigma^{\mathrm{IS}}(\mathrm{v}) \cap \Sigma^{\mathrm{ES}}(\mathrm{v})$. QED

In other words, the AISS allows for more robust predictions about stable coalitions than the conventional sharing rules. 


\subsection{Results for Positive Externality Games}

Lemma 1 and 2 as well as Proposition 1 and 2 did not require any assumption on the property of the partition function. Now, in order to establish further results, we have to be slightly more specific. In section 3, we noted that for some coalitions the free-rider incentive may be so strong that AIVF will share the deficit and not the surplus. Hence, we cannot generally rule out the possibility (though our example in the Appendix does not possess this feature) that in some coalitions members receive less than when all players act as singletons players. Hence, one may be concerned that some AIVFs may lead to payoff vectors which are not individually rational, which would shed some doubts on our concept. Hence, it is informative to know that individual rationality holds for those coalitions that matter. Because only PIS coalitions qualify as potential stable coalitions anyway, Proposition 3 focuses only one this subset of coalitions. It turns out that it suffices to assume only positive externalities (Definition 1).

\section{Proposition 3: AISS and Individual Rationality}

Consider a coalition game $\Gamma(\mathrm{N}, \pi)$ with positive externalities and the class of AIVFs $\mathcal{V}(\Gamma)$. If coalition $\mathrm{S}$ is potentially internally stable, then $\mathrm{S}$ is individually rational for all valuation functions $\mathrm{v}^{\operatorname{AIVF}(\lambda)} \in \mathcal{V}(\Gamma)$ and for all players $i \in \mathrm{N}: \mathrm{v}_{\mathrm{i}}^{\operatorname{AIVF}(\lambda)}(\mathrm{S}) \geq \mathrm{v}_{\mathrm{i}}(\{\mathrm{i}\})$.

Proof: If coalition $\mathrm{S}^{*}$ is potentially internally stable, then for every AIVF it holds that $\forall \mathrm{i} \in \mathrm{S}: \mathrm{v}_{\mathrm{i}}^{\operatorname{AIVF}(\lambda)}\left(\mathrm{S}^{*}\right) \geq \mathrm{v}_{\mathrm{i}}^{\operatorname{AIVF}(\lambda)}\left(\mathrm{S}^{*} \backslash\{\mathrm{i}\}\right)=\pi_{\mathrm{i}}\left(\mathrm{S}^{*} \backslash\{\mathrm{i}\}\right)$ and due to positive externalities $\forall \mathrm{i} \in \mathrm{N}$ : $\pi_{\mathrm{i}}\left(\mathrm{S}^{*} \backslash\{\mathrm{i}\}\right) \geq \pi_{\mathrm{i}}(\{\mathrm{i}\})$. QED

We now turn to our central result related to optimality in the most important sense. It says that adopting an AIVF guarantees that the coalition which generates the highest aggregate worth (i.e. total payoff over all players) among all potentially internally stable coalitions will not only be internally stable but also externally stable and therefore stable. The remarkable aspect of this result is that a sharing scheme that apparently is designed to foster internal stability is also capable of ensuring external stability for those coalitions that are most desirable in terms of the aggregate worth.

\section{Proposition 4: AISS and Optimality}

Let $\Sigma^{\text {PIS }}(\pi)$ be the set of coalitions that are potentially internally stable in coalition game $\Gamma(\mathrm{N}, \pi)$ with positive externalities and let $\mathrm{S}^{*}$ be the coalition with the highest aggregate worth in $\Sigma^{\mathrm{PIS}}(\pi): \forall \mathrm{S} \in \Sigma^{\mathrm{PIS}}(\pi), \mathrm{S} \neq \mathrm{S}^{*}: \pi_{\mathrm{S}^{*}}\left(\mathrm{~S}^{*}\right)+\sum_{\mathrm{j} \in \mathrm{N} \backslash \mathrm{S}^{*}} \pi_{\mathrm{j}}\left(\mathrm{S}^{*}\right) \geq \pi_{\mathrm{S}}(\mathrm{S})+\sum_{\mathrm{j} \in \mathrm{N} \backslash \mathrm{S}} \pi_{\mathrm{j}}(\mathrm{S})$. Then, every valuation function $\mathrm{v}^{\operatorname{AIVF}(\lambda)} \in \mathcal{V}(\Gamma)$ will make coalition $\mathrm{S}^{*}$ both internally and externally stable and, hence, stable. 
Proof: i) Follows from Lemma 1. ii) Assume to the contrary that $S^{*} \in \Sigma^{\mathrm{PIS}}(\pi)$ was not externally stable for some valuation function $\mathrm{v}^{\operatorname{AIVF}(\lambda)} \in \mathcal{V}(\Gamma)$. Hence, it follows from Definition 3 that there exists an outsider $j \in N \backslash S^{*}$ that would strictly gain from joining coalition $S^{*}: v_{j}^{\operatorname{AIVF}(\lambda)}\left(S^{*} \cup\{j\}\right)>v_{j}^{\operatorname{AIVF}(\lambda)}\left(S^{*}\right)$. Using Definition 4 (AIVF), it follows that $\pi_{\mathrm{j}}\left(\mathrm{S}^{*}\right)+\lambda_{\mathrm{j}}\left(\mathrm{S}^{*} \cup\{\mathrm{j}\}\right) \sigma\left(\mathrm{S}^{*} \cup\{\mathrm{j}\}\right)>\pi_{\mathrm{j}}\left(\mathrm{S}^{*}\right)$ and therefore $\sigma\left(\mathrm{S}^{*} \cup\{\mathrm{j}\}\right)>0$ which is equivalent to $\sum_{\mathrm{k} \in \mathrm{S}^{*} \cup\{\mathrm{j}\}} \pi_{\mathrm{k}}\left(\mathrm{S}^{*} \cup\{\mathrm{j}\}\right)>\sum_{\mathrm{k} \in \mathrm{S}^{*} \cup\{\mathrm{j}\}} \pi_{\mathrm{k}}\left(\mathrm{S}^{*}\right)$. Hence, insiders to coalition $\mathrm{S}^{*} \cup\{\mathrm{j}\}$ are strictly better off under $\mathrm{S}^{*} \cup\{\mathrm{j}\}$ than under $\mathrm{S}^{*}$ and $\mathrm{S}^{*} \cup\{\mathrm{j}\}$ is PIS. At the same time, we know from the positive externalities property that outsiders to $S^{*} \cup\{j\}$ are not worse off under $S^{*} \cup\{j\}$ than under $\mathrm{S}^{*}: \quad \sum_{\mathrm{k} \in \mathrm{N} \backslash\left(\mathrm{S}^{*} \cup\{j\}\right)} \pi_{\mathrm{k}}\left(\mathrm{S}^{*} \cup\{\mathrm{j}\}\right) \geq \sum_{\mathrm{k} \in \mathrm{N} \backslash\left(\mathrm{S}^{*} \cup\{j\}\right)} \pi_{\mathrm{k}}\left(\mathrm{S}^{*}\right)$. Combining the inequalities for insiders and outsiders it would hold that $\sum_{\mathrm{k} \in \mathrm{N}} \pi_{\mathrm{k}}\left(\mathrm{S}^{*} \cup\{\mathrm{j}\}\right)>\sum_{\mathrm{k} \in \mathrm{N}} \pi_{\mathrm{k}}\left(\mathrm{S}^{*}\right)$, contradicting the initial assumption that $\mathrm{S}^{*}$ generates the highest worth among all coalitions that are PIS. QED

Proposition 4 can be interpreted as saying that we cannot do better in terms of the total payoff than adopting AISS if the agreement is required to satisfy stability in the sense of d'Aspremont et al. (1983). Note first that this result is very general since it only requires that the underlying game exhibits positive externalities. There is no need for further assumptions like superadditivity and hence this result applies to many interesting economic problems as will be illustrated in section 5. Second, since any AIVF is a parametric valuation function, as it depends upon set of sharing weights $\lambda(\mathrm{S})$, there remains considerable flexibility how to allocate the surplus of the coalition without jeopardizing optimality. According to Proposition 2 , any alternative set of sharing weights would also stabilize the coalition generating the highest aggregate payoff.

\section{Numerical example resumed}

The example in the Appendix confirms that all PIS coalitions are individual rational and that a non-trivial stable coalition exists (see Table 6). Moreover, the AIVF stabilizes the three player coalition $\{a, b, c\}$ with the highest aggregate payoff among all potentially internally stable coalitions (i.e. $131 / 3$ ), achieving $75.5 \%$ of the maximum aggregate payoff obtained in the grand coalition (i.e. $172 / 3$ ). In contrast, the highest aggregate payoff among the conventional sharing rules considered in this example (see Tables A2 to A5) is generated by coalition $\{c, d\}$ with an aggregate payoff of 8 for the Nash bargaining solution with unequal weights (Table A5). This amounts to only $45.3 \%$ of the maximum aggregate payoff.

\subsection{Results for Superadditive Games}

So far we have shown that for AISS a stable coalition generally exists (Proposition 1). Moreover for positive externality games, we have demonstrated that AISS is optimal in that it 
stabilizes the coalition with the highest aggregate worth among those coalitions which could be potentially stabilized at all (Proposition 4). However, so far we do not know under which conditions this positive effect will actual materialize in a coalition game. In other words, we are interested under which conditions AISS has a strictly positive effect. This relates to the condition of the existence of a stable non-trivial coalition.

By consulting the proof of Proposition 1, it is evident that it would be sufficient if there existed at least one non-trivial (i.e. at least a two-player or possibly larger) PIS coalition, i.e.

$\exists \mathrm{S} \subseteq \mathrm{N}: \sigma(\mathrm{S})=\sum_{\mathrm{j} \in \mathrm{S}}\left[\pi_{\mathrm{j}}(\mathrm{S})-\pi_{\mathrm{j}}(\mathrm{S} \backslash\{\mathrm{j}\})\right] \geq 0$. Then, we would have a starting point to apply the "algorithmic existence proof". As we will argue in section 5, in most coalition games of economic interest such a non-trivial PIS coalition does exist. In fact, it will be possible to derive specific conditions that guarantee the existence of a non-trivial PIS coalition. However, in our general context with no structural assumptions about the underlying economic problem, we can only resort to a general condition, which appears to be rather strong.

\section{Proposition 5: AISS and Existence of a Stable Non-Trivial Coalition}

Consider a coalition game $\Gamma(\mathrm{N}, \pi)$ and the class of AIVFs $\mathcal{V}(\Gamma)$. For any $\mathrm{v}^{\operatorname{AIVF}(\lambda)} \in \mathcal{V}(\Gamma)$, there exists at least one stable non-trivial coalition provided $\Gamma(\mathrm{N}, \pi)$ is superadditive.

Proof: Due to superadditivity, $\pi_{\{i, j\}}(\{i, j\}) \geq \pi_{\mathrm{i}}(\{\mathrm{i}\})+\pi_{\mathrm{j}}(\{\mathrm{j}\})$ holds for all coalitions with two members which means that they are PIS. Hence, a proof in the spirit of the proof of Proposition 1 can be constructed, except that the starting point is not the trivial coalition but a coalition with two players. QED

In section 5, we will mention examples where superadditivity does not generally hold but nevertheless a stable non-trivial coalition exists.

\subsection{Negative Externalities}

Let us briefly point out differences and similarities between positive and negative externalities. In the context of negative externality games, no statement in the spirit of Proposition 3 about individual rationality is possible. For members outside coalition $\mathrm{S}$ this is immediately evident as they suffer from the enlargement of coalitions. For the members of $\mathrm{S}$, even superadditivity is not a sufficient property to ensure individual rationality of PIS coalition S. However, this may not seem a problem when considering Propositions 4 and 5.

Proposition 5 stated that a non-trivial coalition exists provided superadditivity holds. As the example in the Appendix shows (see Table A6, column 9), in positive externality games AISS does not ensure a unique stable coalition. This is different in negative externalities: 
superadditivity is a sufficient condition for a unique stable coalition which is the grand coalition. The intuition is that for every AIVF superadditivity makes all coalitions internally stable. ${ }^{10}$ Hence by Lemma 2, every coalition is externally unstable, except for the grand coalition which is externally stable by definition. In other words, there is always an incentive for outsiders to join coalition S, regardless of the members in S. Hence, if we assume that Optimality of Full Cooperation (OFC) holds, i.e. the grand coalition generates the highest aggregate worth among all possible coalitions: $\forall \mathrm{S} \subset \mathrm{N}: \quad \sum_{\mathrm{j} \in \mathrm{N}} \pi_{\mathrm{j}}(\mathrm{N}) \geq \sum_{\mathrm{j} \in \mathrm{N}} \pi_{\mathrm{j}}(\mathrm{S})$, then optimality of AISS also applies to negative externality games.

There are two remarks in order to qualify the optimality result in the case of negative externality games. First, different from positive externality games, we need a stronger condition, namely superadditivity. Second, condition OFC will hold in most games though we mention some models where this is not the case in section 5 .

\section{Applications}

In this section, we will discuss some applications of our results and relate them to models in the literature. We will scrutinize the generality of the properties that we assumed for partition functions. A selection of models found in the literature with associated properties is presented in Table 1.

First, as already pointed out when introducing the notion of the partition function, the bulk of the literature assumes symmetric players. This strongly contrasts with our more general assumption of heterogeneous players. To the best of our knowledge, heterogeneous players have only been analyzed in the context of international environmental agreements (see e.g. footnote 5 for references).

Second, our main result on the optimality of AISS only required the assumption of positive externalities. From Table 1 it is evident that there are many economic examples that belong to this group of games; negative externality games have been analyzed less frequently. One reason is certainly that cooperation is more difficult to establish in positive externality games. In none of the six examples listed under positive externalities is the grand coalition stable. However, in all examples aggregate welfare increases with cooperation, which we call global

10 Formally, consider a superadditive game with negative externalities of coalition formation and assume that coalition $\mathrm{S} \subseteq \mathrm{N}$ would not be internally stable, hence not PIS under the AISS. It follows that (due to negative externalities of coalition formation) $\sum_{\mathrm{j} \in \mathrm{S}} \pi_{\mathrm{j}}(\mathrm{S})<\sum_{\mathrm{j} \in \mathrm{S}} \pi_{\mathrm{j}}(\mathrm{S} \backslash\{\mathrm{j}\})<\sum_{\mathrm{j} \in \mathrm{S}} \pi_{\mathrm{j}}(\{\mathrm{j}\})$ contradicting the initial assumption that $\mathrm{S}$ is superadditive. 
efficiency from cooperation (GEC): $\forall \mathrm{S} \subset \mathrm{N}, \forall \mathrm{i} \in \mathrm{N} \backslash \mathrm{S}: \pi_{\mathrm{S}}(\mathrm{S} \cup\{\mathrm{i}\})+\sum_{\mathrm{j} \in \mathrm{N} \backslash \mathrm{S}} \pi_{\mathrm{j}}(\mathrm{S} \cup\{\mathrm{i}\}) \geq$ $\pi_{\mathrm{S}}(\mathrm{S})+\sum_{\mathrm{j} \in \mathrm{N} \backslash \mathrm{S}} \pi_{\mathrm{j}}(\mathrm{S}) .{ }^{11}$ Consequently, the grand coalition generates the largest aggregate worth in all examples. This stresses the motivation of our paper: it is an important normative research question to search for a class of sharing rules that improves upon the success of cooperation if economic problems are associated with positive externalities and free-riding is therefore a problem.

Third, a strict Pareto-improvement of AISS was associated with the existence of a non-trivial PIS coalition. It is evident from Table 1 that despite superadditivity (which is a sufficient condition for the existence of a non-trivial coalition) does not hold in examples 5 and 8 , a non-trivial stable does nevertheless exist. This stresses our claim in section 4.3 that superadditivity may be a too strong condition in the context of a specific model.

The reasons for the violation of superadditivity are manifold but not unusual in coalition games with externalities. Frequently, the reasons also explain why even if superadditivity holds, free-riding is a problem in positive externality games. ${ }^{12}$ For instance, in text book example of cartels, example 1 in Table 1, an enlargement of the cartel calls for a reduction of the output of its members in equilibrium, which is matched by an increase of output by noncartel members. This "leakage effect" causes that superadditivity may be violated for small coalitions as the number of free-riders is large. Once the cartel assumes the position of Stackelberg leadership as in example 2 in Table 1, leakage effects can be better controlled and hence superadditivity is restored.

Similar leakage effects are also present in most global emission games, as for instance in the empirical model with six world regions in Carraro et al. (2006), cited as example no. 6 in Table 1, though in this particular model superadditivity holds. ${ }^{13}$ Using AISS, Carraro et al. show that the largest stable coalitions comprise only four out of six players. The reason is that coalition members' emissions decrease with an enlargement of the coalition which is contradicted by the optimal response of non-cooperative outsiders which calls for an increase of their emissions as environmental pressure decreases. Hence, despite superadditivity holds in this example, this effect is smaller than the positive externality effect for large coalitions.

11 Positive externalities and superadditivity (Definition 1 and 2) are sufficient (though not necessary) conditions for GEC to hold.

12 This means that the superadditivity effect is dominated by the positive externality effect.

13 Superadditivity does not hold generally in this type of models as long as the coalition does not assume a Stackelberg leader position (Finus 2003). 
In models of $R \& D$ cooperation, example 5 and 8 in Table 1 , the reason for a possible violation of superadditivity is different. In these models, there are two externalities of which the coalition deals only with one. After firms have decided on their membership in the first stage of the coalition game, cooperation on R\&D among coalition members reduces their production costs in the second stage. Following the standard assumption in the literature, coalitions chose R\&D levels as to maximize the worth of their coalition. In example 5 , due to high R\&D-spillovers - meaning that imitation of innovations is easy for outsiders coalitional R\&D efforts also lower outsiders' production costs (positive externality effect). In example 8 model (no R\&D-spillovers to outsiders), this effect is reversed as outsiders' production becomes less competitive compared to insiders' production (negative externality effect). Now, in both models, optimal output of coalition members (i.e. the degree of competition) increases in the third stage due to R\&D-cooperation in the second stage. Since the output externality is not addressed by the coalition in these models, the positive "R\&Dcooperation effect" for coalition members accruing from cooperation may be compensated by the negative competition effect if coalitions become large and therefore superadditivity may be violated.

It is this last example no. 8 that points to the problem of drawing conclusions on the aggregate worth (i.e. aggregate welfare) if not all externalities are part of the strategic game played by coalitions. Then, as example 8 confirms, optimality of the grand coalition cannot be taken for granted. However, this is a general conceptual problem of any kind of welfare measurement beyond the specifics of this model: any externality which is either not captured by a model or is not part of the game about cooperation makes general welfare conclusion difficult. In contrast, for instance in example 7 , our results in section 4.4 directly apply.

\section{Conclusion and Suggestions for Further Research}

In this paper, we have introduced a new sharing scheme for the gains from cooperation in games with externalities that suffer from free-rider problems. We focused on coalition games where the underlying economic problem is associated with positive payoff externalities, but mentioned also results for negative externalities. A prominent example of positive externalities is for instance the provision of public goods. More examples have been discussed in section 5. We established a class of sharing rules, called Almost Ideal Sharing Scheme (AISS), which achieves the maximum aggregate welfare subject to the constraint that coalitions have to be stable. In other words, AISS achieves the highest possible aggregate welfare among the members of the set of coalitions that can be potentially stabilized and of which the grand coalition may, or may not, be a member. Hence, it was conceptually 
important to capture externalities across players and to consider not only the grand coalition but also all other coalitions. Therefore, we based our analysis on the partition function approach and studied stability by invoking the concept of internally and externally stable coalitions introduced by d'Aspremont et al. (1983).

Apart from the important property of AISS for optimality, we demonstrated two other important results. First, AISS guarantees existence of stable coalition. Second, every sharing rule in line with the general concept of AISS leads to the same set of stable coalitions. That is, AISS produces robust results, despite the concept allows for much flexibility in choosing the sharing weights.

Hence, we improved upon the existing literature on coalition formation in the context of externalities by departing from the assumption of symmetric agents, establishing existence of stable coalitions, show a way to make robust predictions about stable coalitions despite the flexibility in the choice of sharing weights and establish optimality subject to stability.

For future research, at least two possible extensions come to our mind. First, our approach could be generalized to allow for the co-existence of several non-trivial coalitions. Of course, multiple coalitions would complicate the analysis tremendously because outside option or threat point payoffs are not straightforwardly defined any longer as threat points are mutually depended and linked. Second, our sharing scheme leaves the choice of surplus sharing weights open. Endogenizing the value of these weights, which may be interpreted as bargaining power, in games with heterogeneous players and externalities seems an interesting topic for further research. 


\section{References}

Altamirano-Cabrera, J.C. and M. Finus (2006), Permit Trading and Stability of International Climate Agreements. "Journal of Applied Economics", vol. 9, pp. 19-48.

Aumann, R.J. and J.H. Drèze (1974), Cooperative Games with Coalition Structures. "International Journal of Game Theory", vol. 3, pp. 217-237.

Barrett, S. (1997), Heterogeneous International Agreements. In: Carraro, C. (ed.), International Environmental Negotiations: Strategic Policy Issues. Edward Elgar, Cheltenham, UK, pp. 9-25.

Barrett, S. (2001), International Cooperation for Sale. "European Economic Review”, vol. 45 (10), pp. 1835-1850.

Bloch, F. (2003), Non-Cooperative Models of Coalition Formation in Games with Spillovers. In: Carraro, C. (ed.), Endogenous Formation of Economic Coalitions, Edward Elgar, Cheltenham, UK, ch. 2, pp. 35-79.

Bolger, E.M. (1989), A Set of Axioms for a Value for Partition Function Games. "International Journal of Game Theory", vol. 18, pp. 37-44.

Bosello, F., B. Buchner and C. Carraro (2003), Equity, Development, and Climate Change Control. "Journal of the European Economic Association", vol. 1 (2-3), pp. 601-611.

Botteon, M. and C. Carraro (1997), Burden-Sharing and Coalition Stability in Environmental Negotiations with Asymmetric Countries. In: Carraro, C. (ed.), International Environmental Negotiations: Strategic Policy Issues. Edward Elgar, Cheltenham et al., ch. 3, pp. 26-55.

Carraro, C., J. Eyckmans and M. Finus (2006), Optimal Transfers and Participation Decisions in International Environmental Agreements. "Review of International Organizations", vol. 1, 2006, pp. 379-396.

Chander, P. and H. Tulkens (1995), A Core-Theoretic Solution for the Design of Cooperative Agreements on Transfrontier Pollution. "International Tax and Public Finance", vol.2, pp. 279-293.

Chander, P. and H. Tulkens (1997), The Core of an Economy with Multilateral Environmental Externalities. "International Journal of Game Theory", vol. 26, pp. 379-401.

d'Aspremont, C., A. Jacquemin, J. J. Gabszewicz and J. A. Weymark (1983), On the Stability of Collusive Price Leadership. "Canadian Journal of Economics", vol. 16 (1), pp. 17-25. 
de Clippel, G. and R. Serrano (2005), Marginal Contributions and Externalities in the Value". Working paper 2005-11, Brown University.

Deneckere, R. and C. Davidson (1985), Incentives to Form Coalitions with Bertrand Competition. "Rand Journal of Economics", vol. 16, pp. 473-486

Donsimoni, m.-P., N.S. Econnomides and H.M. Polemarchakis (1986), Stable Cartels. “International Economic Review”, vol. 27, pp. 317-327.

Eyckmans, J. and M. Finus (2007), Measures to Enhance the Success of Global Climate Treaties. "International Environmental Agreements", vol. 7, 2007, pp. 73-97.

Finus, M. (2003), Stability and Design of International Environmental Agreements: The Case of Transboundary Pollution. In: Folmer, H. and T. Tietenberg (eds.), International Yearbook of Environmental and Resource Economics, 2003/4, Edward Elgar, Cheltenham, UK, ch. 3, pp. 82-158.

Kohler, M. (2002), Coalition Formation in International Monetary Policy Games. "Journal of International Economics", vol. 56, pp. 371-385.

Maskin, E. (2003), Bargaining, Coalitions, and Externalities. Mimeo, paper presented at the EEA-ESEM Meeting in Stockholm, August 20-24, 2003.

Meyerson, R.B. (1977), Values of Games in Partition Function Form. "International Journal of Game Theory", vol. 6, pp. 23-31.

Poyago-Theotokay, J. (1995), Equilibrium and Optimal Size of A Research Joint Venture in an Oligopoly with Spillovers. “The Journal of Industrial Economics”, Vol. 43, S. 209-226.

Sandler T. (2004), Global Collective Action. Cambridge University Press, Cambridge.

Thrall, R. and W. Lucas (1963), n-person games in partition function form, "Naval Research Logistics Quarterly", vol. 10, pp. 281-298.

Weikard, H.-P., M. Finus and J. C. Altamirano-Cabrera (2006), The Impact of Surplus Sharing on the Stability of International Climate Coalitions. "Oxford Economic Papers", vol. 58, 2006, pp. 209-232.

Yi, S.-S. (1996), Endogenous Formation of Customs Unions under Imprefect Competition: Open Regionalism is Good. "Journal of International Economics", vol. 41, pp. 153-177.

Yi, S.-S. (1997), Stable Coalition Structures with Externalities. "Games and Economic Behavior", vol. 20 (2), pp. 201-237.

Yi, S.-S. (1998), Endogenous Formation of Joint Ventures with Efficiency Gains. "Rand Journal of Economics", vol. 29, pp. 610-631. 
Yi, S.-S. (2003), Endogenous Formation of Economic Coalitions: A Survey of the Partition Function Approach. In: Carraro, C. (ed.), Endogenous Formation of Economic Coalitions, Edward Elgar, Cheltenham, UK, ch. 3, pp. 80-127.

Yi, S.-S. and H. Shin (2000), Endogenous Formation of Research Coalitions with Spillovers. "International Journal of Industrial Organization", Vol. 18, S. 229-256. 


\section{Appendix}

Table A1 displays a four player example where the partition function exhibits positive externalities and superadditivity (see Definition 1 and 2 in the text) as this can be easily checked. The table displays the members of coalition $\mathrm{S}$ (column 1), the worth to coalition $\mathrm{S}$ (column 2) and non-members in S (column 3-6) and the aggregate worth to all players (column 7), the sum of free-rider payoffs (column 8), the surplus of the coalition (column 9; Definition 4) which is the difference between column 8 and 2 and indicates coalitions that are (not) potentially internally stable coalitions with 1 (0) (column 10).

Table A1: Partition Function

\begin{tabular}{l|ccccc|c|ccc}
\hline \multicolumn{1}{c}{$(1)$} & $(2)$ & $(3)$ & $(4)$ & $(5)$ & $(6)$ & $(7)$ & $(8)$ & $(9)$ & $(10)$ \\
coalition $\mathrm{S}$ & $\pi_{\mathrm{S}}(\mathrm{S})$ & $\pi_{\mathrm{a}}(\mathrm{S})$ & $\pi_{\mathrm{b}}(\mathrm{S})$ & $\pi_{\mathrm{c}}(\mathrm{S})$ & $\pi_{\mathrm{d}}(\mathrm{S})$ & $\sum_{\mathrm{j}} \pi_{\mathrm{j}}(\mathrm{S})$ & $\sum_{\mathrm{j} \in \mathrm{S}} \pi_{\mathrm{j}}(\mathrm{S} \backslash\{\mathrm{j}\})$ & $\sigma(\mathrm{S})$ & $\Sigma^{\mathrm{PIS}}$ \\
\hline Singletons & - & 0 & 0 & 0 & 0 & 0 & - & - & 1 \\
\hline$\{\mathrm{a}, \mathrm{b}\}$ & 1 & - & - & 1 & 1 & 3 & 0 & 1 & 1 \\
$\{\mathrm{a}, \mathrm{c}\}$ & 1 & - & $21 / 3$ & - & $31 / 3$ & $62 / 3$ & 0 & 1 & 1 \\
$\{\mathrm{a}, \mathrm{d}\}$ & $21 / 3$ & - & 1 & 2 & - & $51 / 3$ & 0 & $21 / 3$ & 1 \\
$\{\mathrm{~b}, \mathrm{c}\}$ & 3 & $31 / 3$ & - & - & 1 & $71 / 3$ & 0 & 3 & 1 \\
$\{\mathrm{~b}, \mathrm{~d}\}$ & 1 & $31 / 3$ & - & 2 & - & $61 / 3$ & 0 & 1 & 1 \\
$\{\mathrm{c}, \mathrm{d}\}$ & 1 & 1 & 6 & - & - & 8 & 0 & 1 & 1 \\
\hline$\{\mathrm{a}, \mathrm{b}, \mathrm{c}\}$ & 9 & - & - & - & $41 / 3$ & $131 / 3$ & $62 / 3$ & $21 / 3$ & 1 \\
$\{\mathrm{a}, \mathrm{b}, \mathrm{d}\}$ & $51 / 3$ & - & - & 3 & - & $81 / 3$ & $51 / 3$ & 0 & 1 \\
$\{\mathrm{a}, \mathrm{c}, \mathrm{d}\}$ & $51 / 3$ & - & 7 & - & - & $\left.12 \frac{1}{3}\right\}$ & $61 / 3$ & -1 & 0 \\
$\{\mathrm{~b}, \mathrm{c}, \mathrm{d}\}$ & 8 & $41 / 3$ & - & - & - & $121 / 3$ & 9 & -1 & 0 \\
\hline$\{\mathrm{a}, \mathrm{b}, \mathrm{c}, \mathrm{d}\}$ & $172 / 3$ & - & - & - & - & $172 / 3$ & $182 / 3$ & -1 & 0 \\
\hline
\end{tabular}

We display valuations for the Shapley value and the Nucleolus in Table A2 and A3. Both concepts are the extended versions as defined in Aumann and Drèze (1974), meaning that these values are computed not only for the grand coalition but for every nonempty coalition $\mathrm{S} \subseteq \mathrm{N}$. The numbers for the Shapley value were computed according to the following formula:

$[1 \mathrm{~A}] \quad \mathrm{v}_{\mathrm{i}}^{\text {Shap }}(\mathrm{S})=\sum_{\mathrm{T} \subseteq \mathrm{S}} \frac{[\mathrm{t}-1] ![\mathrm{s}-\mathrm{t}] !}{\mathrm{t} !}\left[\pi_{\mathrm{T}}(\mathrm{T})-\pi_{\mathrm{T} \backslash\{i\}}(\mathrm{T} \backslash\{\mathrm{i}\})\right] \forall \mathrm{i} \in \mathrm{S}$

where $\mathrm{T}$ is a subset of players in $\mathrm{S}$, recalling $\mathrm{s}=\# \mathrm{~S}$ and noting that, similarly, $\mathrm{t}=\# \mathrm{~T}$. Intuitively, the Shapley value gives every player of coalition $\mathrm{S}$ its average contribution to every possible subcoalition $\mathrm{T}$ of $\mathrm{S}$. 
For the Nucleolus, there does not exist an easy explicit formula for the four player case. We therefore calculated the Nucleolus payoffs by solving for each coalition $\mathrm{S}$ the following linear programming problem:

[2A]

$$
\begin{gathered}
\max _{\delta,\left\{\mathrm{v}_{\mathrm{j}}(\mathrm{S})\right\}_{\mathrm{j} \in \mathrm{S}}} \delta \\
\text { subject to }\left\{\begin{array}{l}
\sum_{\mathrm{j} \in \mathrm{T}} \mathrm{v}_{\mathrm{j}}(\mathrm{T})+\delta \leq \pi_{\mathrm{T}}(\mathrm{T}) \quad \forall \mathrm{T} \subset \mathrm{S}, \mathrm{T} \neq \varnothing \quad \text { changed } \\
\sum_{\mathrm{j} \in \mathrm{S}} \mathrm{v}_{\mathrm{j}}(\mathrm{S})=\pi_{\mathrm{S}}(\mathrm{S}) \\
\mathrm{v}_{\mathrm{j}}(\mathrm{S}) \geq 0 \quad \forall \mathrm{j} \in \mathrm{N}
\end{array}\right.
\end{gathered}
$$

where $\delta=\sum_{\mathrm{j} \in \mathrm{T}} \mathrm{v}_{\mathrm{j}}(\mathrm{T})-\pi_{\mathrm{T}}(\mathrm{T})$ can be interpreted as the excess that subcoalition $\mathrm{T} \subset \mathrm{S}$ can achieve under valuation function $\mathrm{v}$ and coalition $\mathrm{S}$ compared to its stand alone value $\pi_{\mathrm{T}}(\mathrm{T})$. Therefore, the solution to the maximization problem yields the maximum equal excess that that can be guaranteed to every proper subcoalition $T \subset S$. The numbers $v_{j}^{\text {Nucl }}$ in each row of Table A3 are given by the components of vector $\left\{\mathrm{v}_{\mathrm{j}}(\mathrm{S})\right\}_{\mathrm{j} \in \mathrm{S}}$ that is part of the solution to problem $[2 \mathrm{~A}]$ for the corresponding coalition $\mathrm{S}$.

In Table A4 and A5, valuations for the Nash Bargaining solution are computed and displayed based on

$$
\mathrm{v}_{\mathrm{i}}^{\mathrm{Nash}-\mathrm{B}}(\mathrm{S})=\pi_{\mathrm{i}}(\{\mathrm{i}\})+\lambda_{\mathrm{i}}\left[\pi_{\mathrm{S}}(\mathrm{S})-\sum_{\mathrm{i} \in \mathrm{S}} \pi_{\mathrm{i}}(\{\mathrm{i}\})\right], \sum_{\mathrm{j} \in \mathrm{S}} \lambda_{\mathrm{j}}=1 \text { changed }
$$

where we assume equal weights in Table A4, i.e., $\lambda_{\mathrm{j}}=1 / \mathrm{s}$, and unequal weights in Table A5 with $\omega_{\mathrm{a}}=1, \omega_{\mathrm{b}}=2, \omega_{\mathrm{c}}=3$ and $\omega_{\mathrm{d}}=4, \lambda_{\mathrm{i}}=\omega_{\mathrm{i}} / \sum_{\mathrm{jes}} \omega_{\mathrm{j}}$.

Table A6 displays valuations for the AIVF as defined in Definition 4 in the text, assuming equal weights, i.e., $\lambda_{\mathrm{j}}=1 / \mathrm{s}$. Note that the weights do not matter given the robustness result in Proposition 2.

Tables A2 to A6 list the members of coalition S (column 1), valuations of all players for a given coalition S (column 2-5), aggregate valuations (column 6), internally stable coalitions (column 7), externally stable coalitions (column 8) and stable coalitions (column 9). 
Table A2: Valuation Function for the Shapley Value*

\begin{tabular}{|c|c|c|c|c|c|c|c|c|}
\hline $\begin{array}{c}\text { (1) } \\
\text { coalition } \mathrm{S}\end{array}$ & $\begin{array}{c}(2) \\
\mathrm{v}_{\mathrm{a}}^{\text {Shap }}(\mathrm{S})\end{array}$ & $\begin{array}{c}(3) \\
\mathrm{v}_{\mathrm{b}}^{\text {Shap }}(\mathrm{S}) \\
\end{array}$ & $\begin{array}{c}(4) \\
\mathrm{v}_{\mathrm{c}}^{\text {Shap }}(\mathrm{S}) \\
\end{array}$ & $\begin{array}{c}(5) \\
\mathrm{v}_{\mathrm{d}}^{\text {Shap }}(\mathrm{S}) \\
\end{array}$ & $\sum_{j}^{(6)} \mathrm{v}_{j}(\mathrm{~S})$ & $\begin{array}{l}(7) \\
\Sigma^{\mathrm{IS}} \\
\end{array}$ & $\begin{array}{l}(8) \\
\Sigma^{\mathrm{ES}}\end{array}$ & $\begin{array}{l}\text { (9) } \\
\Sigma^{\mathrm{S}}\end{array}$ \\
\hline Singletons & 0 & 0 & 0 & 0 & 0 & 1 & 0 & 0 \\
\hline$\{a, b\}$ & $1 / 2$ & $1 / 2$ & 1 & 1 & 3 & 1 & 0 & 0 \\
\hline$\{a, c\}$ & $1 / 2$ & $2 \frac{1}{3}$ & $1 / 2$ & $31 / 3$ & $62 / 3$ & 1 & 0 & 0 \\
\hline$\{\mathrm{a}, \mathrm{d}\}$ & $11 / 6$ & 1 & 2 & $11 / 6$ & $51 / 3$ & 1 & 0 & 0 \\
\hline$\{b, c\}$ & $31 / 3$ & $11 / 2$ & $11 / 2$ & 1 & $71 / 3$ & 1 & 0 & 0 \\
\hline$\{\mathrm{b}, \mathrm{d}\}$ & $31 / 3$ & $1 / 2$ & 2 & $1 / 2$ & $61 / 3$ & 1 & 0 & 0 \\
\hline$\{c, d\}$ & 1 & 6 & $1 / 2$ & $1 / 2$ & 8 & 1 & 0 & 0 \\
\hline$\{\mathrm{a}, \mathrm{b}, \mathrm{c}\}$ & $21 / 3$ & $31 / 3$ & $31 / 3$ & $4 \frac{1}{3}$ & $131 / 3$ & 0 & 1 & 0 \\
\hline$\{\mathrm{a}, \mathrm{b}, \mathrm{d}\}$ & 2 & $11 / 3$ & 3 & 2 & $81 / 3$ & 0 & 0 & 0 \\
\hline$\{\mathrm{a}, \mathrm{c}, \mathrm{d}\}$ & 2 & 7 & $1 \frac{1}{3}$ & 2 & $12 \frac{1}{3}$ & 0 & 1 & 0 \\
\hline$\{b, c, d\}$ & $4 \frac{1}{3}$ & 3 & 3 & 2 & $12 \frac{1}{3}$ & 0 & 1 & 0 \\
\hline$\{\mathrm{a}, \mathrm{b}, \mathrm{c}, \mathrm{d}\}$ & 4 & 5 & 5 & $32 / 3$ & $172 / 3$ & 0 & 1 & 0 \\
\hline
\end{tabular}

* Valuations are computed based on the partition function in Table 1, applying equation [1A].

Table A3: Valuation Function for the Nucleolus*

\begin{tabular}{|c|c|c|c|c|c|c|c|c|}
\hline $\begin{array}{c}\text { (1) } \\
\text { coalition } \mathrm{S}\end{array}$ & $\begin{array}{c}(2) \\
\mathrm{v}_{\mathrm{a}}^{\mathrm{Nucl}}(\mathrm{S})\end{array}$ & $\begin{array}{c}(3) \\
\mathrm{v}_{\mathrm{b}}^{\text {Nucl }}(\mathrm{S})\end{array}$ & $\begin{array}{c}(4) \\
\mathrm{v}_{\mathrm{c}}^{\mathrm{Nucl}}(\mathrm{S}) \\
\end{array}$ & $\begin{array}{c}(5) \\
v_{d}^{\text {Nucl }}(S)\end{array}$ & $\sum_{j}^{(6)} \mathrm{v}_{j}(\mathrm{~S})$ & $\begin{array}{l}(7) \\
\Sigma^{\mathrm{IS}}\end{array}$ & $\begin{array}{l}(8) \\
\Sigma^{\mathrm{ES}}\end{array}$ & $\begin{array}{l}(9) \\
\Sigma^{\mathrm{S}}\end{array}$ \\
\hline Singletons & 0 & 0 & 0 & 0 & 0 & 1 & 0 & 0 \\
\hline$\{a, b\}$ & $1 / 2$ & $1 / 2$ & 1 & 1 & 3 & 1 & 0 & 0 \\
\hline$\{a, c\}$ & $1 / 2$ & $2 \frac{1}{3}$ & $1 / 2$ & $31 / 3$ & $62 / 3$ & 1 & 0 & 0 \\
\hline$\{\mathrm{a}, \mathrm{d}\}$ & $1 \frac{1}{6}$ & 1 & 2 & $1 \frac{1}{6}$ & $51 / 3$ & 1 & 1 & 1 \\
\hline$\{b, c\}$ & $31 / 3$ & $11 / 2$ & $11 / 2$ & 1 & $71 / 3$ & 1 & 0 & 0 \\
\hline$\{b, d\}$ & $31 / 3$ & $1 / 2$ & 2 & $1 / 2$ & $61 / 3$ & 1 & 0 & 0 \\
\hline$\{c, d\}$ & 1 & 6 & $1 / 2$ & $1 / 2$ & 8 & 1 & 0 & 0 \\
\hline$\{a, b, c\}$ & $12 / 3$ & $32 / 3$ & $32 / 3$ & $4 \frac{1}{3}$ & $131 / 3$ & 0 & 1 & 0 \\
\hline$\{\mathrm{a}, \mathrm{b}, \mathrm{d}\}$ & $21 / 6$ & 1 & 3 & $21 / 6$ & $81 / 3$ & 0 & 0 & 0 \\
\hline$\{\mathrm{a}, \mathrm{c}, \mathrm{d}\}$ & $21 / 6$ & 7 & 1 & $21 / 6$ & $12 \frac{1}{3}$ & 0 & 1 & 0 \\
\hline$\{\mathrm{b}, \mathrm{c}, \mathrm{d}\}$ & $4 \frac{1}{3}$ & $31 / 3$ & $3 \frac{1}{3}$ & $11 / 3$ & $12 \frac{1}{3}$ & 0 & 1 & 0 \\
\hline$\{a, b, c, d\}$ & $35 / 12$ & $55 / 12$ & $55 / 12$ & $35 / 12$ & $172 / 3$ & 0 & 1 & 0 \\
\hline
\end{tabular}

* Valuations are computed based on the partition function in Table 1A by solving for each coalition $\mathrm{S}$ the linear programming problem [2A]. 
Table A4: Valuation Function for the Nash Bargaining Solution: Equal Weights*

\begin{tabular}{|c|c|c|c|c|c|c|c|c|}
\hline $\begin{array}{c}\text { (1) } \\
\text { coalition S }\end{array}$ & $\begin{array}{c}(2) \\
\mathrm{v}_{\mathrm{a}}^{\text {Nucl }}(\mathrm{S})\end{array}$ & $\begin{array}{c}(3) \\
\mathrm{v}_{\mathrm{b}}^{\text {Nucl }}(\mathrm{S})\end{array}$ & $\begin{array}{c}(4) \\
v_{c}^{\text {Nucl }}(S)\end{array}$ & $\begin{array}{c}(5) \\
\mathrm{v}_{\mathrm{d}}^{\mathrm{Nucl}}(\mathrm{S})\end{array}$ & $\sum_{j}^{(6)} \mathrm{v}_{j}(\mathrm{~S})$ & $\begin{array}{l}(7) \\
\Sigma^{\mathrm{IS}}\end{array}$ & $\begin{array}{l}(8) \\
\Sigma^{\mathrm{ES}}\end{array}$ & $\begin{array}{l}\text { (9) } \\
\Sigma^{\mathrm{S}}\end{array}$ \\
\hline Singletons & 0 & 0 & 0 & 0 & 0 & 1 & 0 & 0 \\
\hline$\{a, b\}$ & $1 / 2$ & $1 / 2$ & 1 & 1 & 3 & 1 & 0 & 0 \\
\hline$\{a, c\}$ & $1 / 2$ & $21 / 3$ & $1 / 2$ & $31 / 3$ & $62 / 3$ & 1 & 0 & 0 \\
\hline$\{\mathrm{a}, \mathrm{d}\}$ & $11 / 6$ & 1 & 2 & $11 / 6$ & $51 / 3$ & 1 & 0 & 0 \\
\hline$\{b, c\}$ & $31 / 3$ & $11 / 2$ & $11 / 2$ & 1 & $71 / 3$ & 1 & 0 & 0 \\
\hline$\{\mathrm{b}, \mathrm{d}\}$ & $31 / 3$ & $1 / 2$ & 2 & $1 / 2$ & $61 / 3$ & 1 & 0 & 0 \\
\hline$\{\mathrm{c}, \mathrm{d}\}$ & 1 & 6 & $1 / 2$ & $1 / 2$ & 8 & 1 & 0 & 0 \\
\hline$\{a, b, c\}$ & 3 & 3 & 3 & $4 \frac{1}{3}$ & $131 / 3$ & 0 & 1 & 0 \\
\hline$\{\mathrm{a}, \mathrm{b}, \mathrm{d}\}$ & $17 / 9$ & $17 / 9$ & 3 & $17 / 9$ & $81 / 3$ & 0 & 1 & 0 \\
\hline$\{\mathrm{a}, \mathrm{c}, \mathrm{d}\}$ & $17 / 9$ & 7 & $17 / 9$ & $17 / 9$ & $12 \frac{1}{3}$ & 0 & 1 & 0 \\
\hline$\{\mathrm{b}, \mathrm{c}, \mathrm{d}\}$ & $4 \frac{1}{3}$ & $22 / 3$ & $22 / 3$ & $22 / 3$ & $12 \frac{1}{3}$ & 0 & 1 & 0 \\
\hline$\{\mathrm{a}, \mathrm{b}, \mathrm{c}, \mathrm{d}\}$ & $45 / 12$ & $45 / 12$ & $45 / 12$ & $45 / 12$ & $172 / 3$ & 0 & 1 & 0 \\
\hline
\end{tabular}

* Valuations are computed based on the partition function in Table 1A, applying equation [3A] with equal weights $\lambda_{\mathrm{j}}=1 / \mathrm{s}$.

Table A5: Valuation Function for the Nash Bargaining Solution: Unequal Weights*

\begin{tabular}{|c|c|c|c|c|c|c|c|c|}
\hline $\begin{array}{c}\text { (1) } \\
\text { coalition S }\end{array}$ & $\begin{array}{c}(2) \\
v_{\mathrm{a}}^{\text {Nucl }}(\mathrm{S})\end{array}$ & $\begin{array}{c}(3) \\
\mathrm{v}_{\mathrm{b}}^{\text {Nucl }}(\mathrm{S})\end{array}$ & $\begin{array}{c}(4) \\
\mathrm{v}_{\mathrm{c}}^{\text {Nucl }}(\mathrm{S})\end{array}$ & $\begin{array}{c}(5) \\
v_{d}^{\text {Nucl }}(S)\end{array}$ & $\sum_{j}^{(6)} \mathrm{v}_{j}(S)$ & $\begin{array}{l}(7) \\
\Sigma^{\mathrm{IS}}\end{array}$ & $\begin{array}{l}(8) \\
\Sigma^{\mathrm{ES}}\end{array}$ & $\begin{array}{l}\text { (9) } \\
\Sigma^{\mathrm{S}}\end{array}$ \\
\hline Singletons & 0 & 0 & 0 & 0 & 0 & 1 & 0 & 0 \\
\hline$\{a, b\}$ & $1 / 3$ & $2 / 3$ & 1 & 1 & 3 & 1 & 0 & 0 \\
\hline$\{\mathrm{a}, \mathrm{c}\}$ & $1 / 4$ & $2 \frac{1}{3}$ & $3 / 4$ & $31 / 3$ & $62 / 3$ & 1 & 0 & 0 \\
\hline$\{\mathrm{a}, \mathrm{d}\}$ & $7 / 15$ & 1 & 2 & $113 / 1528 / 15$ & $51 / 3$ & 1 & 0 & 0 \\
\hline$\{b, c\}$ & $31 / 3$ & $6 / 5$ & $9 / 5$ & 1 & $71 / 3$ & 1 & 0 & 0 \\
\hline$\{b, d\}$ & $31 / 3$ & $1 / 3$ & 2 & $2 / 3$ & $61 / 3$ & 1 & 0 & 0 \\
\hline$\{c, d\}$ & 1 & 6 & $3 / 7$ & $4 / 7$ & 8 & 1 & 1 & 1 \\
\hline$\{a, b, c\}$ & $11 / 2$ & 3 & $41 / 2$ & $41 / 3$ & $131 / 3$ & 0 & 0 & 0 \\
\hline$\{\mathrm{a}, \mathrm{b}, \mathrm{d}\}$ & $16 / 21$ & $111 / 21$ & 3 & $31 / 21$ & $81 / 3$ & 0 & 0 & 0 \\
\hline$\{a, c, d\}$ & $2 / 3$ & 7 & 2 & $22 / 3$ & $12 \frac{1}{3}$ & 0 & 1 & 0 \\
\hline$\{b, c, d\}$ & $41 / 3$ & $17 / 9$ & $22 / 3$ & $35 \%$ & $12 \frac{1}{3}$ & 0 & 1 & 0 \\
\hline$\{\mathrm{a}, \mathrm{b}, \mathrm{c}, \mathrm{d}\}$ & $123 / 30$ & $316 / 30$ & $53 / 10$ & $71 / 15$ & $172 / 3$ & 0 & 1 & 0 \\
\hline
\end{tabular}

* Valuations are computed based on the partition function in Table 1A, applying equation [3A] with unequal weights with $\omega_{\mathrm{a}}=1, \omega_{\mathrm{b}}=2, \omega_{\mathrm{c}}=3, \omega_{\mathrm{d}}=4$ and $\lambda_{\mathrm{i}}(\mathrm{S})=\omega_{\mathrm{i}} / \sum_{\mathrm{j} s \mathrm{~s}} \omega_{\mathrm{j}}$. 
Table A6: Almost Ideal Valuation Function: Equal Weights*

\begin{tabular}{|c|c|c|c|c|c|c|c|c|}
\hline$(1)$ & (2) & (3) & (4) & (5) & (6) & (7) & (8) & (9) \\
\hline coalition S & $\mathrm{v}_{\mathrm{a}}^{\mathrm{AISS}}(\mathrm{S})$ & $\mathrm{v}_{\mathrm{b}}^{\mathrm{AISS}}(\mathrm{S})$ & $\mathrm{v}_{\mathrm{c}}^{\mathrm{AISS}}(\mathrm{S})$ & $\mathrm{v}_{\mathrm{d}}^{\mathrm{AISS}}(\mathrm{S})$ & $\sum_{\mathrm{j}} \mathrm{v}_{\mathrm{j}}(\mathrm{S})$ & $\Sigma^{\mathrm{IS}}$ & $\Sigma^{\mathrm{ES}}$ & $\Sigma^{\mathrm{S}}$ \\
\hline Singletons & 0 & 0 & 0 & 0 & 0 & 1 & 0 & 0 \\
\hline$\{a, b\}$ & $1 / 2$ & $1 / 2$ & 1 & 1 & 3 & 1 & 0 & 0 \\
\hline$\{a, c\}$ & $1 / 2$ & $21 / 3$ & $1 / 2$ & $31 / 3$ & $62 / 3$ & 1 & 0 & 0 \\
\hline$\{\mathrm{a}, \mathrm{d}\}$ & $1 \frac{1}{6}$ & 1 & 2 & $11 / 6$ & $51 / 3$ & 1 & 1 & 1 \\
\hline$\{b, c\}$ & $31 / 3$ & $11 / 2$ & $11 / 2$ & 1 & $71 / 3$ & 1 & 0 & 0 \\
\hline$\{b, d\}$ & $31 / 3$ & $1 / 2$ & 2 & $1 / 2$ & $61 / 3$ & 1 & 1 & 1 \\
\hline$\{c, d\}$ & 1 & 6 & $1 / 2$ & $1 / 2$ & 8 & 1 & 1 & 1 \\
\hline$\{a, b, c\}$ & $41 / 9$ & $31 / 9$ & $17 / 9$ & $4 \frac{1}{3}$ & $13 \frac{1}{3}$ & 1 & 1 & 1 \\
\hline$\{\mathrm{a}, \mathrm{b}, \mathrm{d}\}$ & $31 / 3$ & 1 & 3 & 1 & $81 / 3$ & 1 & 1 & 1 \\
\hline$\{\mathrm{a}, \mathrm{c}, \mathrm{d}\}$ & $2 / 3$ & 7 & $12 / 3$ & 3 & $12 \frac{1}{3}$ & 0 & 1 & 0 \\
\hline$\{\mathrm{b}, \mathrm{c}, \mathrm{d}\}$ & $4 \frac{1}{3}$ & $52 / 3$ & $12 / 3$ & $2 / 3$ & $12 \frac{1}{3}$ & 0 & 1 & 0 \\
\hline$\{a, b, c, d\}$ & $41 / 12$ & $63 / 4$ & $23 / 4$ & $41 / 12$ & $172 / 3$ & 0 & 1 & 0 \\
\hline
\end{tabular}

- Valuations are computed based on the partition function in Table A1, applying Definition 4 in the text, assuming $\lambda_{j}=1 / s$. 
Tabel 1: Overview of Coalition Games with Externalities

\begin{tabular}{|c|c|c|c|c|c|}
\hline & & $\begin{array}{l}\text { Stable Non- } \\
\text { trivial Coalitions }\end{array}$ & SAD & GEC & Comment \\
\hline \multicolumn{6}{|c|}{ Positive Externality Games } \\
\hline \multicolumn{6}{|c|}{ Symmetry } \\
\hline 1 & Output cartel with linear demand and linear cost functions & no & no & yes & PEP: Yi (1997), SAD and GEC: own comp. \\
\hline 2 & $\begin{array}{l}\text { Output cartel (Stackelberg leadership) with linear demand and } \\
\text { linear cost functions }\end{array}$ & yes & yes & yes & own comp. \\
\hline 3 & $\begin{array}{l}\text { Price cartel with linear demand and imperfect substitutes as well } \\
\text { as linear cost functions }\end{array}$ & yes & yes & yes & $\begin{array}{l}\text { Deneckere and Davidson (1985); PEP: Theorem 1, } \\
\text { SAD: Corollary to Theorem. 4: GEC: } \rightarrow \text { SAD }\end{array}$ \\
\hline 4 & $\begin{array}{l}\text { Price leadership cartel with linear demand and quadratic cost } \\
\text { functions }\end{array}$ & yes & yes & yes & $\begin{array}{l}\text { Donsimoni et al. }(1986)^{1} \text {; PEP: Lemma 1, SAD: } \\
\text { own comp., GEC: } \rightarrow \text { SAD }\end{array}$ \\
\hline 5 & R\&D cooperation with large spillovers and output competition & yes & no & yes & $\begin{array}{l}\text { Poyago-Theotokay (1995)²; SAD: Figure 5, GEC: } \\
\text { Figure 6, PEP: Yi and Shin (2000): Prop. } 1\end{array}$ \\
\hline \multicolumn{6}{|c|}{ Heterogeneity } \\
\hline 6 & $\begin{array}{l}\text { Global emission game with net benefits defined as benefits from } \\
\text { global emissions minus abatement costs from individual } \\
\text { emissions }\end{array}$ & yes & yes & yes & $\begin{array}{l}\text { Carraro et al. (2006); PEP, SAD: section 2.4, } \\
\text { GEC: } \rightarrow \text { SAD } \\
\text { Altamirano-Cabrera and Finus (2006); PEP, SAD: } \\
\text { section C, GEC: } \rightarrow \text { SAD }\end{array}$ \\
\hline & Negative Externality Games, Symmetry & $\begin{array}{l}\text { Stable Non- } \\
\text { trivial Coalitions }\end{array}$ & SAD & OFC & Comment \\
\hline 7 & $\begin{array}{l}\text { Customs unions, no tariffs within coalition, uniform external tariff } \\
\text { towards outsiders }\end{array}$ & yes, grand coalition & yes & yes & $\begin{array}{l}\text { Yi }(1996)^{3} \text {; NEP: Proposition } 3 \text { and 6, SAD: } \\
\text { Proposition 4, OGC: Proposition. } 5\end{array}$ \\
\hline 8 & $\begin{array}{l}\text { Joint ventures ( } \approx \text { R\&D cooperation with no spillovers) and output } \\
\text { competition }\end{array}$ & yes, grand coalition & - & - & $\begin{array}{l}\text { Yi }(1998)^{3} \text { : NEP: Proposition 2, SAD, OFC: } \\
\text { depends on parameters of the model }\end{array}$ \\
\hline
\end{tabular}

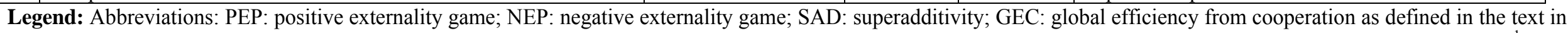
section $5 ; \rightarrow$ : follows from; own comp.: own computations which are available upon request; OFC: optimality of full cooperation as defined in the text in section $4.4 ;{ }^{1}$ This

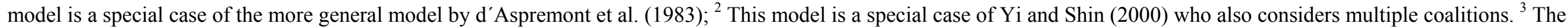
partition function comprises also multiple coalitions in this paper. 